\title{
Mapping design knowledge: 36 years of Design Studies
}

\author{
Kathryn Burns ${ }^{a^{*}}$, Jack Ingram ${ }^{b}$, Louise Annable \\ ${ }^{a}$ Birmingham City University \\ ${ }^{\mathrm{b}}$ Formerly Birmingham City University \\ *Corresponding author e-mail: kathryn.burns@bcu.ac.uk
}

\begin{abstract}
:
This paper examines the nature of design research, knowledge and theory, as revealed through an overview of the areas of interest that make up published writing on design, specifically that published in Design Studies, since its first publication in 1979. The research proposes a taxonomy of design knowledge addressing the objects, processes and practices of design and consumption. This is used as the basis to trace the history and development of design ideas and design writing over the following 36 years through classifying the issues that are central to the published papers published in Design Studies, and quantifying the changes of emphasis in design topics over that period.
\end{abstract}

The paper offers proposals for the areas within which design theory resides, suggests that until a mature design epistemology evolves the concept of epistemics is a more appropriate term and reflects on the relationship between design research, knowledge, theory and practice.

Keywords: design research; design knowledge; design theory; epistemology

\section{Introduction}

This paper intends to map design knowledge as a basis for informing three separate but interlinked strands of research.

Firstly, it responds to this conference's call to explore 'what has changed over the last 50 years in the field of design research?'. Taking Design Studies as an exemplar of published design writing, it plots the shifts and interests in design research and knowledge over the 36 years to 2015. First published in 1979, Design Studies is the longest published academic 
design journal written in English, thus providing a rich and longitudinal source of material from which to undertake such a mapping exercise.

Secondly, the original research was undertaken as part of the designing and consuming project - expressing design knowledge for academics from other disciplines. Here, the stimulus was the potential for theoretical development at the interface of science and technology studies, design and the sociology of consumption.

Creative cross-fertilisation between these fields promised to enrich and extend the understanding of the relation between design and consumption and the dynamics of both. The theory of science and technology studies and the sociology of consumption were well defined, with a canon presenting accepted conventions. Indeed, some of the established concepts in those areas, such as 'assembly', 'appropriation', 'scripting' and 'normalisation' matched with concepts from design and have been published elsewhere (Ingram et al, 2007, Shove et al, 2007).

At the time of the study, the researchers felt that in comparison, generally accepted, or published, concepts from design theory were few and the body of literature small (Annable, 2007).

The third and final strand is the increasing need for design researchers to evidence nonacademic impact. For example, the UK Research Excellence Framework (REF2014, 2012) required case studies demonstrating the impact of research on its external environment. The outcome of design research should be a product or process that is then used by a target group to improve the user experience or provide other benefits. In exploring the impact of design, there is a need to understand what design knowledge is in order to create mechanisms for transfer and exploitation. The impact from design is explored further by Burns et al (2014).

Therefore, this mapping exercise should provide a basis for a conversation across academic subject boundaries. It also needs to be uncomplicated in order to promote use of design knowledge in a non-academic context. Thus, the basic understanding of what the knowledge is may allow the development of better constructed boundary objects for transfer into the wider world.

In addition to these strands of research there is a surprising paucity of literature regarding what the actual constituents of design knowledge are. Notable exceptions are the work of Cross in 1982 and 1999, following that of Archer in 1981. Both are used as basis of a design taxonomy in this work.

In discussing the design literature and research in 1981 Archer notes that there is a limited range of topics'. He goes on:

"The British journal Design Studies was published by IPC in cooperation with the Design Research Society partly as a response to these limitations, but this journal is only half-way into its second year at the time of writing, so that it is a little soon to be 
able to judge from the 40 or so articles published there what will be the boundaries and centres of interest of Design Research reflected by it."

It is the intention of this paper, 34 years on, to explore the articles now published and reflect on what their issues, concerns, findings and conclusions say about 50 years of design knowledge.

\section{Building a taxonomy of design knowledge}

In this research two assumptions have been made:

- In common with other areas, design research generates knowledge and out of that published knowledge comes theory.

- Design journals reflect the interests and priorities of their constituencies, providing a path along which to trace the development and evolution of design ideas.

In order to map this evolution a framework or taxonomy is needed through which published works may be categorised. Given that design covers many fields, eg, architecture, fashion, graphics, product and software, as well as many interests, such as process, pedagogy, user centred design and the philosophy of design, the literature was scanned for an existing taxonomy of design knowledge. With no definitive version available, this work has developed its own, informed by the work of Archer (1981) and Cross (1982, 1999). In 1981, in his paper for the Portsmouth Conference Design: science: method, Archer describes the work of the then Department of Design Research at the Royal College of Art, London, UK. In examining the titles of the studies of his fellow researchers, Archer posits 10 areas of design research. These are given in Figure 1.

He then reduces these to three:

Design phenomenology to include design history, taxonomy and technology;

Design praxiology including design modelling and metrology; and

Design philosophy to include design axiology, espistemology and pedagogy.

Archer (1981)

In 1999, Cross states:

"Our concern in design research has to be the development, articulation and communication of design knowledge. Our axiom has to be that there are forms of knowledge peculiar to the awareness and ability of a designer.

"Where do we look for this knowledge? I believe that it has three sources: people, processes and products."

He then proposes a taxonomy of design research comprising:

- design epistemology - study of designerly ways of knowing;

- design praxiology - study of the practices and processes of design; 
- design phenomology - study of the form and configuration of artefacts;

Cross (1999).

1. Design history: the study of what is the case, and how things came to be the way they are, in the design area.

2. Design taxonomy: the study of the classification of phenomena in the design area.

3. Design technology: the study of the principles underlying the operations of the things and systems comprising designs.

4. Design praxiology: the study of the nature of design activity, its organisation and its apparatus.

5. Design modelling: the study of the human capacity for the cognitive modelling, externalisation and communication of design ideas.

6. Design metrology: the study of measurement in relation to design phenomena, with special emphasis on the handling of non-quantitative data.

7. Design axiology: the study of worth in the design area, with special regard to the relations between technical, economic, moral, social and aesthetic values.

8. Design philosophy: the study of the logic of disclosure on matters of concern in the design area.

9. Design epistemology: the study of the nature and validity of ways of knowing, believing and feeling in the design area.

10. Design pedagogy: the study of the principles and practice of education in the matter of concern to the design area.

Figure 1 - The 10 areas of design knowledge Archer (1981)

The usefulness of this proposal lies in the suggestion that there is formal knowledge structure. Here, we suggest, a coherent theory of design (epistemology) is posited alongside the more tacit knowledge embedded in design practice and the products of that practice.

Therefore Cross's definition of design praxiology has been adopted for this study. Added to his definition of design phenomenology is the study of artefacts in use and the symbolic meanings that are ascribed to them.

However, the phrase 'design epistemology' suggests formal knowledge structures in the field of design and a well-articulated epistemology would be an indication of design having reached maturity as an established academic discipline. 
Therefore, 'epistemics' is suggested and used as a more appropriate alternative for an emerging academic discipline.

The final categories of knowledge used for the mapping exercise were based on the above and augmented following an initial attempt at categorisation. The resulting and final taxonomy is as follows.

Design praxiology: the study of the practice and processes of design, including its organisation and apparatus and design activity. Includes: design process; design process models (external); modelling (prototyping); metrology (study of measurement in relation to design phenomena and an emphasis on handling of non-quantitative data); case studies and reflective practice; design management; concept design.

Design phenomenology: the study of the form and configuration of artefacts, their use and symbolic meanings. Includes: technology and implications of new technology on design; design morphology (theoretical studies of development of form and shape); semantics and syntax of form; efficiency and economy in product design; relationships between form and context (including ergonomics and user-centred design); environmental design (including sustainability and design for recycling design for mass customisation.

Design epistemics: the study of design knowledge, and the construction of formal models of the processes - perceptual, intellectual and linguistic - by which design knowledge and understanding are achieved and communicated. Includes: design discourse (overviews, philosophy of design, design methodology, history and research); design language; axiology: study of worth (values) including their origin, nature, and classification (this includes technical, economic, moral, social, aesthetic, hedonic and prudential values); design thinking (including cognitive modelling of internal design processes); design ability (theories and reflections on nature of, including creativity); social aspects of design (including collaboration); pedagogy (design education and how people learn to design)

\section{Methodology}

Having established a design knowledge taxonomy, the work moved to categorising all the published research articles in Design Studies. As described above design knowledge is generated by design research and out of that published knowledge comes theory. Design Studies was chosen as representative of all forms of design research, and the longest established of the design journals of note.

From its website [http://www.journals.elsevier.com/design-studies/]

\footnotetext{
"Design Studies is a leading international academic journal focused on developing understanding of design processes. It studies design activity across all domains of application, including engineering and product design, architectural and urban design, computer artefacts and systems design. It therefore provides an interdisciplinary forum for the analysis, development and discussion of fundamental aspects of design activity, from cognition and methodology to values and philosophy."
} 
All the Design Studies research papers, including title, abstract and key words, were read and classified according to the authors' explicit focus, or the researchers' interpretation where the central focus was less explicit.

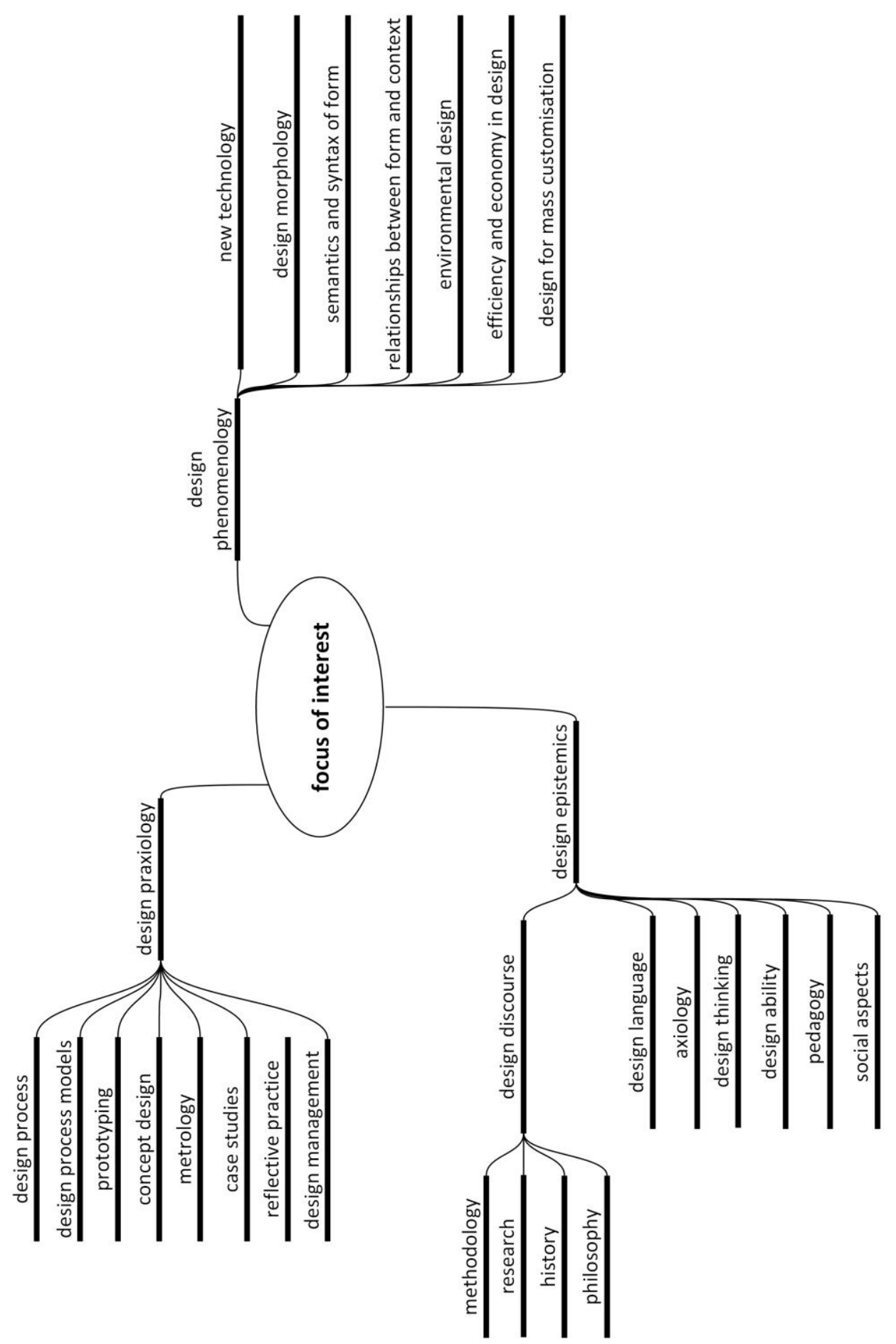

Figure 2 The design knowledge taxonomy 
The classification attempted to elicit the new knowledge contained within each paper. For example, if concerned with methodologies for teaching aspects of professional practice based on extensive case studies of a particular designer, a paper would be judged to be concerned with pedagogical matters (classed as design epistemics). If the case studies were previously unpublished, it would also be categorised as design practice (classed under praxiology). Thus, if appropriate, some papers were assigned to more than one classification, so that the total percentages of papers can exceed $100 \%$ in the charts given below.

This work took place in two distinct phases. The first was that undertaken for the original design and consuming project and covered the period 1979 to 2005 . This work was written up, but has not been published previously. However, it did inform other outputs from the project, eg, Ingram et al (2007), Shove et al (2007).

The second part of the research covered the period 2006 to 2015. This was undertaken by a different researcher from the first part of the work - possibly forming a discontinuity in the results. However, the latter researcher had been involved in a peripheral role with the original work and was familiar with its working practices and methods. Additionally, the original research notes and papers have been studied by the later researcher, in order to minimise differences and discrepancies.

Each volume of Design Studies was analysed separately in order to provide a year-by-year breakdown of popular topics. Additionally, the special issues were listed to provide another source for analysis.

The findings and results from the analysis are presented in the following section.

\section{Findings}

Figure 3 shows the breakdown of the papers from Design Studies over the period 1979 to 2015 according to the three main categories of design epistemics; design praxiology and design phenomenology.

This shows that overall design epistemics, or the study of design knowledge, has been the most popular topic of discussion, with design praxiology a close second for many years, but in the last three years it has dropped off markedly. Design phenomenology, including the study of the form and configuration of artefacts, has received far less attention from design researchers than the other two subjects. The emphasis is on discourse about how designers think and what they do. This drive towards understanding design, its theory and its practice, may reflect the relative youth of design as an area of academic study and may illustrate the eagerness for a more developed intellectual culture in design. Whatever the case, the data suggest that design epistemics and design praxiology have attracted considerably more attention from design researchers than have the objects that designers produce.

A more detailed breakdown is provided in Figures 4, 5 and 6. These show the top two topics for each year since 1979 . 


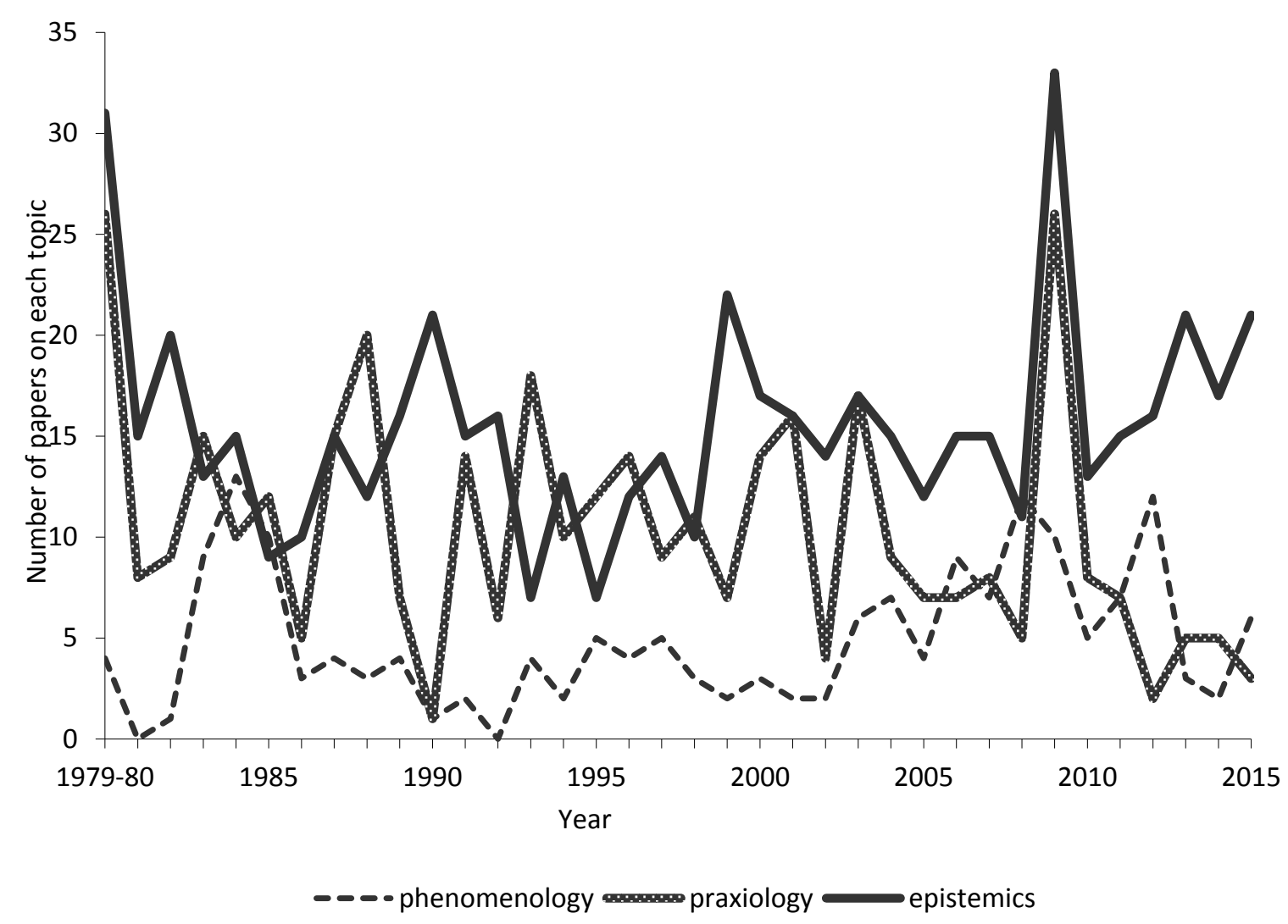

Figure 3 Tracking the focus of interest: Design Studies 1979-2015

In undertaking the classification of the research papers published in Design Studies, it was found to be relatively easy to determine which overall category a paper fell into, but much harder to determine its specific location. So, for example, a paper about working in teams based on a study of student behaviours would be categorised as design epistemics, but then deciding if it contributed to design thinking, social practices in design, pegdagogy, and/or design research methods could be more difficult. Although, the research methodology allowed papers to be attributed to more than one category, this was not always useful in measuring the popularity or significance of individual topics. It was also noted that often the keywords chosen by the authors were not those most appropriate to the content of the paper. Additionally, words could be used to mean different things. For example, in Design Studies, design thinking refers to cognitive processes. Outside of design research it usually describes an aspect of design management relating to idea creation and selection.

The apparent predominance of epistemics may be explained by the desire to provide a theoretical grounding in papers that start from a phenomenological or praxiological perspective. It is to be expected that academic journals encourage even the most casespecific of accounts to connect to more generalised theory. 
Most of the praxiology papers are more concerned with design practice than user practices. The object and the user together seem under-represented in the mass of design writing that has been approximated into the categories above.

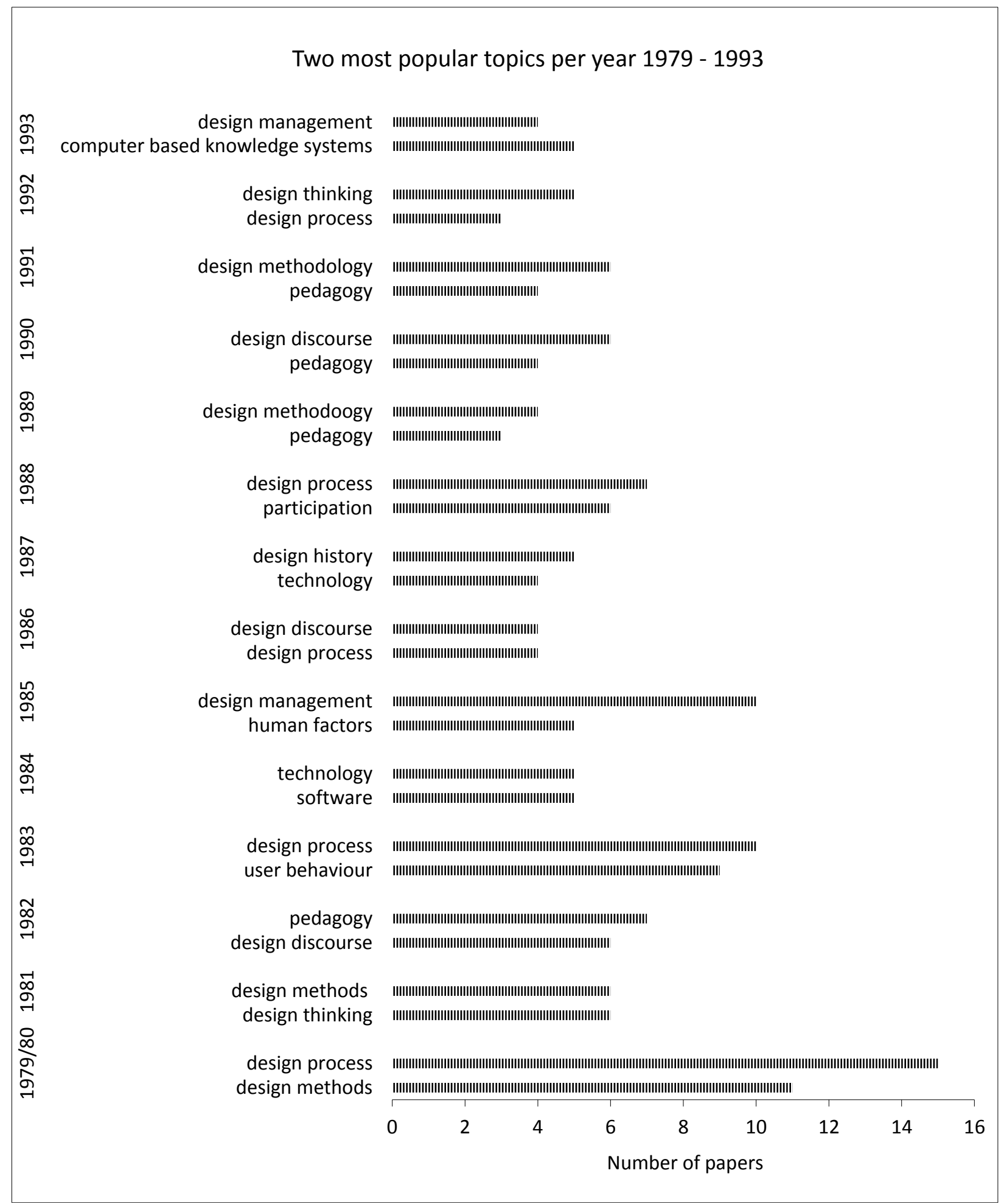

Figure 4 Two most popular topics each year: Design Studies $1979-1993$ 


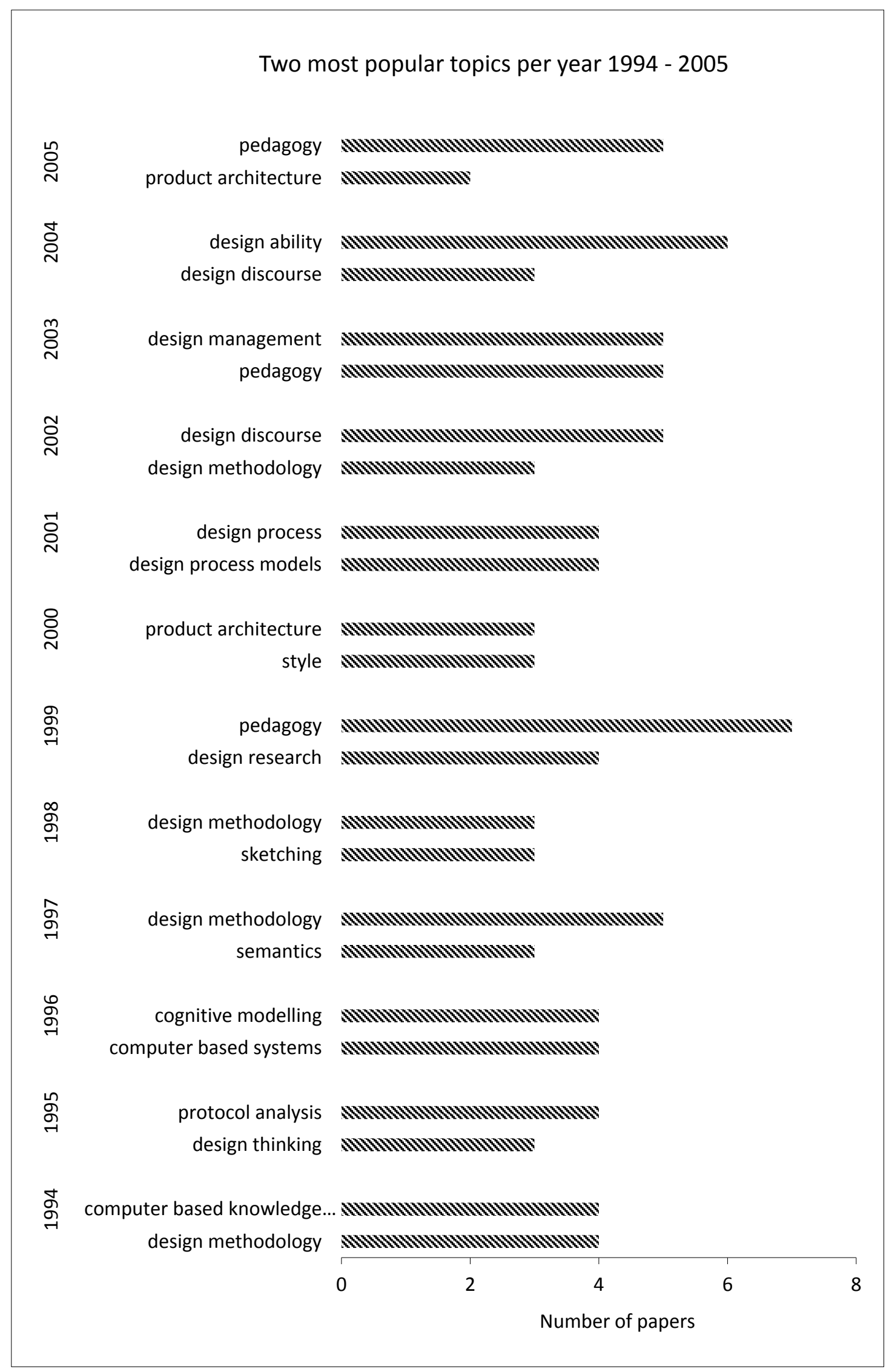

Figure 5 Two most popular topics each year: Design Studies 1994-2005 
Two most popular topics per year 2006 - 2015

$\begin{array}{rr}\stackrel{n}{\sim} & \text { collaborative design } \\ \text { design discourse } & \text { design thinking } \\ \stackrel{\sim}{\sim} & \text { design discourse } \\ & \text { collaborative design }\end{array}$

$\stackrel{m}{\stackrel{m}{s}}$

collaborative design

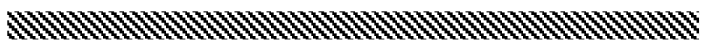

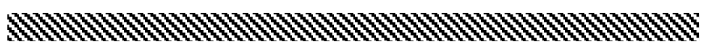

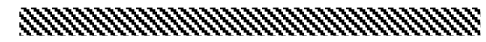

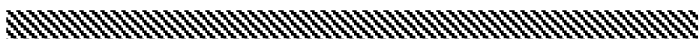

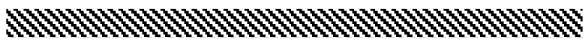

$\stackrel{m}{\stackrel{m}{N} \text { design thinking }}$

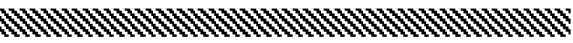

design discourse

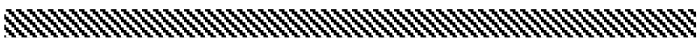

user-centred design

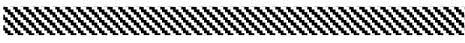

ํํำ

collaborative design

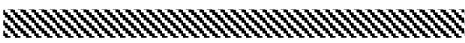

design discourse

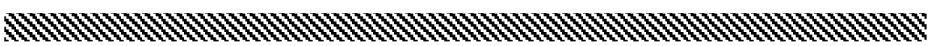

궁

design process

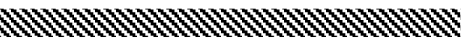

design thinking

$\$ \ldots \ldots \ldots \ldots \ldots$

pedagogy $\$ \ldots \ldots \ldots \ldots$

웅

design discourse

design process

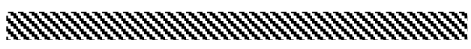

$\begin{array}{rr}\text { ㅇํㄴ } & \text { pedagogy } \\ & \text { design thinking }\end{array}$

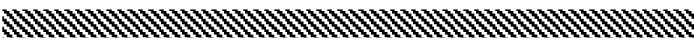

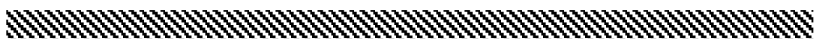

\$.

$\stackrel{\infty}{\circ}$

new technology implications

NONONONON

user-centred design

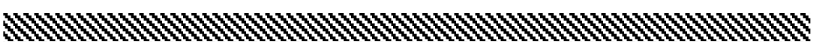

ㅇํㅇ

design discourse

$\$ \ldots \ldots \ldots \ldots \ldots \ldots \ldots \ldots$

user-centred design

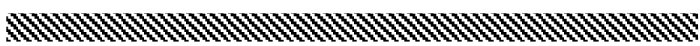

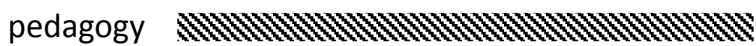

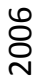

design thinking

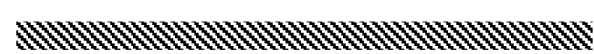

new technology implications

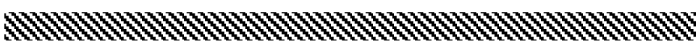

\begin{tabular}{lllllllll}
\hline 0 & 1 & 2 & 3 & 4 & 5 & 6 & 7 & 8
\end{tabular}

Number of papers

Figure 6 Two most popular topics each year: Design Studies 2006-2015 
The changing interests in design can also be found in the special issues of Design Studies, which addressed what were seen as the key topics in design over the period under review:

Table 1 Design Issues - special issues 1983 onwards

\begin{tabular}{lc}
\hline Topic & Year vol:issue \\
\hline Designing for behaviour & 1983 4:2 \\
\hline Information technology & 1984 5:2 \\
\hline Case studies & 1993 14:4 \\
\hline Analysing design activity & 1995 16:2 \\
\hline Design cognition and computation & $199617: 4$ \\
\hline Descriptive models of design & 1997 18:4 \\
\hline Ethnography and engineering & $200021: 4$ \\
\hline Collaboration & $200021: 3$ \\
\hline Common Ground (design research) & $200324: 6$ \\
\hline Design expertise & $200425: 5$ \\
\hline Digital design & $200627: 3$ \\
\hline Participatory design & $200728: 3$ \\
\hline $\begin{array}{l}\text { Interaction design and creative practice (software } \\
\text { systems to support creative work) }\end{array}$ & $200829: 6$ \\
\hline $\begin{array}{l}\text { Design thinking (from Design Thinking Research } \\
\text { Symposium 2007) }\end{array}$ & $200930: 2$ \\
\hline $\begin{array}{l}\text { Software design (from workshop Studying } \\
\text { professional software Design 2010) }\end{array}$ & $201031: 6$ \\
\hline $\begin{array}{l}\text { Interpreting design thinking (from Design } \\
\text { Thinking Research Symposium 2010) }\end{array}$ & $201132: 6$ \\
\hline Studying design in practice & $201233: 6$ \\
\hline $\begin{array}{l}\text { Articulating design thinking (from Design Thinking } \\
\text { Research Symposium 2012) }\end{array}$ \\
\hline
\end{tabular}

This shows a strong focus on design thinking, mirrored unsurprisingly in the top two topics for each year. This is a sub category of epistemics, so contributing to the predominance of this area in the mapping exercise.

As stated by Cross (2015) the focus of Design Studies "is on studies concerned with the process of designing". Thus, the journal publishes research that provides "new insight into or knowledge about the design process, or assists new development of the processes of designing", Cross (2015). This focus is reflected in the findings, but they may indicate other features as discussed below. 


\section{Discussion}

So, to what extent can design theory be mapped? Do the categories of design knowledge provide a basis for a more comprehensive classification of design theory? What light does this mapping exercise throw upon the relationship between research, knowledge, theory and practice in the field of design? Is there a clear picture of the development of design knowledge over the last 50 years? Do the findings above provide any insights regarding multi-disciplinary design or its impact in a non-academic arena?

The first area to explore is why design epistemics is seen as more popular than design praxiology or design phenemonology. With its focus on 'designerly ways of knowing' (Cross, 1999) including the philosophy of design and design thinking, it is likely that this is seen as the more academic route and more likely to meet the requirements of research funding and research assessment exercises, eg, REF2014 (2012).

Indeed, the influence of the research councils in promoting targeted research agendas through funding initiatives with resultant increases in the number of publications in those areas can be observed in published work. Tracking these past influences could be the subject of future work.

In their work in undertaking a bibliometric analysis of Design Studies over the period 1996 to 2010, Chai and Xaio (2012) find the two most common areas are design process and design cognition (part of design thinking). As discussed above, design thinking has been prevalent in the map of Design Studies, particularly being featured in a number of special issues.

However, design processes have not been covered much at all in last 10 years.

Another explanation for the predominance of epistemics may lay in the tacit nature of much design knowledge. Design activity is largely based on a collection of craft skills relying on know-how rather than explicit, formal methodological rules. Equally, design generates artefacts that are an embodiment of knowledge from many sources. Tacit knowledge, then, is a relatively large portion of all design knowledge. Interpretation of design practice and products in order to draw out the tacit is a major source of theoretical constructs.

Therefore, designers might be expected to be more interested in the objects that they design, and, as Cross $(1982,1999)$ discusses, important design knowledge is contained within objects, in terms of attributes, exemplars for future iterations of the design, materials and forms.

The relatively few papers that can be classed as design phenomenology suggests that either this knowledge has not been made as explicit as other types, or that the authors are not designers and so publish in areas other than design research. Further, it is possible that designers do not see their practice based work as research and so do not publish in academic journals.

As stated in the introduction to this paper, there is an assumption underpinning the exercise that, as in other areas, research generates knowledge and that out of published knowledge 
comes theory. In turn, theory forms the basis for the education and hence professional practice of both design practitioners and researchers. However, it is recognised that in design the use of theory as a basis for professional practice is not as clear as in some other subjects. Due to much knowledge being tacit, while there a linkage between research, knowledge, theory and practice can be detected, the linkage is not linear, and practice, rather than being driven by theory, is itself the driver.

Indeed, much of the design theory that exists is derived from the results of research that seeks to explain design practice. To the extent that design theory does influence design practice, the influence has largely been indirect, through the structuring of design education, rather than by its conscious adoption by practitioners.

In adopting and adapting Cross's categories, this work supports the notion that product design theory can be developed from design practice based on tacit knowledge, either through reflection on the design practice by the practitioner or through protocol analysis.

However, the research/knowledge/theory/practice relationship is far from transparent. Designing is an activity that is focused on generating new things. At times, novelty that challenges assumptions and values, whether at a level of concept or detail of execution, can be a measure of success. In this drive towards creation of the new, the following of precedent, respect for convention and adherence to theoretical rules are less important than in some other professions such as law, medicine or engineering. When compared with more academic subjects, including sociology, the linkage between research, knowledge, theory and practice is dominated by practice and efforts to understand it.

Product design is driven by a hunger for new, commercially successful products. Designers work at the intersections of interest groups and stakeholders, juggling complex conflicting requirements in the quest for realisable, intelligible concepts. Even the most mundane of everyday products is a nexus of technological, social, financial and ethical systems, and designers will consciously balance aspects of these whilst unconsciously accommodating others.

In conducting the mapping exercise of Design Studies a number of topics were notably absent. Of particular note are design management and the interests of the user, expressed in terms such as user-centred design, interaction design and user experience design. This is probably due to a number of specialist journals where these topics predominate.

The paper focuses on categorising papers published in Design Studies according to a taxonomy of design knowledge. This provides a prima facia representative expression of design research concerns over 36 years. The categories were found useful for differentiating between publications and organisations on the basis of their focus and for tracking shifting patterns of interest. Further, the need to generate sub-categories helped in identifying areas of like and unlike when compared to theories in social science.

Tacit design knowledge is bound up in both designed products and the design practices that produce them. In that existing products have a major role in defining the starting point for 
new design activity, they are boundary objects that facilitate dialogue between designers, consumers and manufacturers. At different stages of design process, drawings, models and prototypes are boundary objects between functions within the manufacturing organisation. At all stages of design process, artefacts embody the knowledge of the organisation. The concept of tacit knowledge embodied in artefacts is more than a neat way to approach theory. It is the stuff upon which business is built, recognised through the patents and design registrations that assign ownership of the intellectual property (the knowledge) that the artefacts represent. In his study of knowledge boundaries in new product development, Carlile refers to Bourdieu (1977) and Lave (1988), when describing knowledge as localized, embedded and invested in practice (Carlile, 2002). These boundary objects are crucial in transferring design knowledge, to result in impact, Burns et al (2014). However, it is not clear that academic design research encourages their study or codification.

\section{Conclusions}

The research has found that a development of the terms proposed by Cross and Archer provides a useful basis for categorising design research, knowledge and theory. Using the categories to classify papers published in Design Studies gives some insight into how the overall field of design theory has changed and developed over the last 50 years.

Design has a relatively short history of academic writing and to fill this gap design writers and theorists have traditionally used other disciplines as a source of ideas that they can apply to design practice and design thinking. These imported ideas are from a range of disciplines, including the social sciences and management. The mapping of design theory is one step in the other direction.

As for the relationship between research, knowledge, theory and practice, there is a case to be made that whereas in sociology (and many other disciplines) practice follows theory, which in turn is based on the knowledge that comes from research, the same linkage is not found in design. Here, it is more generally the case that design practice takes little notice of theory. Theory is built on knowledge that comes out of research, but research is largely driven by a desire to make explicit the tacit knowledge that is embedded in design practice and the outcomes of that practice. Design practice, in drawing principally on tacit knowledge, largely bypasses a formal acknowledgement of theory.

Further work could map design knowledge as exhibited by other journals, such as, Design Issues and The Design Journal, that published in books and that discussed the numerous design conferences over the last 50 years.

As stated by Bruce (1981)

"Whilst Design Research can, and does, enjoy the unifying characteristics of being 'systematic enquiry whose goal is knowledge of, or in, the area of human experience, skill and understanding that reflects man's concern with the enhancement of order, utility, value and meaning in his habitat', it is nevertheless even less reasonable to regard it as a single discipline than it is to regard scientific enquiry or literary 
scholarship as a single discipline. The sub-disciplines which go to make it up will no doubt continue to expand, divide and reform over time, in the way that science and scholarship have expanded, divide and reformed."

This work has shown how those sub-divisions have fared over the last 36 years. The next decades will prove interesting to see how things develop going forward.

Acknowledgements: the original work for this paper was funded through the ESRC/AHRC research project 'Designing and Consuming: Objects, Practices and Processes' (award no. RES-154-25-0011).

Thanks go to Professor Elizabeth Shove, University of Lancaster, and Dr Matthew Watson, University of Sheffield, for their significant contribution to the project and its outcomes.

\section{References}

Annable, A. (2007). Mapping design theory. Unpublished - available from the corresponding author

Archer, L. B. (1981). A view of the nature of design research, in Jacques, R and Powell, J A (eds) Design: science: method Guildford: Westbury House:

Burns, K., Rowe, D., Snell, R. (2014). Exploring impact through seating design. Design Management in an Era of Disruption 19th DMI: Academic Design Management Conference London, September 2014 (pp 2642 - 2658) ISBN 978-0-615-99152-8 Boston: Design Management Institute

Bourdieu, P. (1977). (orig. 1972) Outline of a theory of practice. Cambridge, UK: Cambridge University Press

Carlile, R. P. (2002). A pragmatic view of knowledge and boundaries: boundary objects in new product development. Organisational Science, Vol.13, No. 4, pp 442-455

Chai, K., Xiao, X. (2012). Understanding design research: a biliometric anlysis of Design Studies (1996 - 2010). Design Studies Vol 33 pp 24-43

Cross, N. (1982). Designerly ways of knowing. Design Studies Vol 3 pp 221-227

Cross, N. (1999). Design research: a disciplined conversation. Design Issues Vol 15, No. 2, pp 5-10

Cross, N. (2006). Designerly ways of knowing. London: Springer

Cross, N. (2015). Editorial. Design Studies Vol 36 pp 1-2

Ingram, J., Shove, E., \& Watson, M. (2007). Products and Practices: Selected Concepts from Science and Technology Studies and from Social Theories of Consumption and Practice. Design Issues, 23(2), pp 3-16.

Lave, J. (1988). Cognition in practice: Mind, mathematics and culture in everyday life. Cambridge, UK: Cambridge University Press

REF2014 (2012). Panel criteria and working methods. Retrieved 16 March 2016 from http://www.ref.ac.uk/

Shove, E., Watson, M., Hand, M., \& Ingram, J. (2007). The design of everyday life. Oxford: Berg

About the Authors:

Kathryn Burns is an associate professor in the Faculty of Arts, Design and Media. She has led a number of major projects linking the University with industry. With a focus on building design awareness and usage, these projects have assisted over 500 companies. 
Jack Ingram is Emeritus Professor of Design at Birmingham City University. Current interests focus on the nexus of philosophy, economics and human evolution. He is co-author of The Design of Everyday Life (2007), London: Berg.

Louise Annable was research team leader with Design Knowledge Network at the University from 2003 to 2009 and the research assistant for the Designing and Consuming project. She now runs her own company Bookity, repurposing used books as a range of giftware. 